\title{
Influence of resolution on elevation and slope at watershed scale in Loess Plateau
}

\author{
Wang Chunmei ${ }^{1}$, Yang Qinke ${ }^{1 *}$, Liu Hongyan², Guo Weiling ${ }^{3}$, David LB Jupp ${ }^{4}$, Li Rui ${ }^{3}$ \\ From 2010 International Conference on Combating Land Degradation in Agricultural Areas (ICCLD'10) \\ Zi'An City, PR China. 11-15 October 2010
}

\begin{abstract}
This article studied the effects of resolution on elevation and slope using Statistical and Geostatistical methods. Xian' Nan watershed in Loess Plateau was taking as the study area. The base data was a 1:10000 topographic map and the resolutions studied in this paper included $5 \mathrm{~m}, 25 \mathrm{~m}$ and $50 \mathrm{~m}$. The results showed that: (1) for elevation and slope data, the mean value, STD value, histogram and semi-variogram changed with resolution reduction. The mean value, STD value became smaller in both elevation and slope cases. Histograms moved to the left which shows there was a decrease of elevation and slope with resolution. The sill for semi-variograms of elevation and slope decreased with resolution reduction; (2) the changes of Mean value; STD and histogram were greater in elevation data than in slope data. (3) By using the Independent Structure model, the semi-variogram could be modeled by 4 components for elevation data and the semi-variogram could be modeled by 3 components for slope data. There was more information in slope than in elevation in the components with short range (short wave-length) information. (4) The influence of resolution reduction was greater in the components with short range, so the degree of influence of resolution reduction was related to the amount of short wave-lengths information. The results of this paper had shown which information was lost with resolution reduction and the reason for the different changes on mean value, STD and histogram for elevation and slope. It could also be used to explain different scaling effects in different terrain areas in the future.
\end{abstract}

\section{Introduction}

Digital Elevation Models (DEM) is widely used as a digital representation of terrain. Terrain models include important factors for soil erosion and hydrology, etc. [1-3]. DEM resolution is one of the most important factors that influence the ability of a DEM to represent terrain. That is because as resolution becomes coarser, many of the terrain indexes that derived from the DEM will change. Elevation and Slope are two of the most important terrain factors in many study fields $[4,5]$. Many researchers have paid attention to the change of terrain factors with DEM resolution reduction such as Chang and Tsai (1991) [6], Gao (1997) [7], Zhang (1999) [8], Wolock (2000) [9] and Wu et al. (2008) [10]. Their results showed that slope tended to become smaller in most of areas with resolution reduction.

\footnotetext{
* Correspondence: qkyang@nwu.edu.cn

${ }^{1}$ College of Urban and Environmental Science, Northwest University, Xi'an,

Shaanxi 710027 China

Full list of author information is available at the end of the article
}

But there is not yet sufficient study on why there are differences between terrain factors derived from fine resolution DEM and from coarse resolution DEM and which part of the information has been lost with resolution reduction. Geostatistics has been widely applied to study fields such as vegetation investigation, soil characteristic analyses, etc. Some researchers have used geostatistical analyses to study spatial patterns in topography [11]. In this research the authors studied the structure of terrain and the change in terrain structure with resolution reduction by investigating changes in each component of the semi-variogram. The study uses Xian' Nan watershed as the study area. This watershed is located in Loess Hilly area in Loess Plateau in China. The authors studied the differences between elevation and slope derived from DEMs with resolutions of $5 \mathrm{~m}, 25 \mathrm{~m}$ and $50 \mathrm{~m}$.

The aim of this research is to show which information "disappears" or "reduces" when resolution becomes coarser. This may help explain why terrain factors

\section{SpringerOpen ${ }^{\circ}$}


change with resolution and understand the terrain characteristics which change with resolution.

\section{Material and methods Study area}

The study area is the Xian' Nan watershed located in the Hilly area of the Loess Plateau (E109 $11^{\prime}-109^{\circ} 22^{\prime}$, N36 $42^{\prime}-36^{\circ} 47^{\prime}$ ) (Figure 1). This watershed covers an area of $44 \mathrm{~km}^{2}$ with an average altitude of $1220 \mathrm{~m}$. It is a typical hilly landform in the Loess Plateau with a complex surface configuration and crossing gullies. The ground slope is steep with an average gradient of $28^{\circ}$.

\section{Base data and data processing}

The base data is a topographic map at 1:10,000 scale issued by China's National Bureau of Surveying and Mapping in 1981 with a contour interval of $5 \mathrm{~m}$ which covers the whole study area. The data processing includes topographic map digitizing, projection transformation, check in elevation values, check in river directions and Lake Boundaries. The projection for the base data is
Krasovsky_1940_Albers. Longitude of the Central Meridian is E105. The first Standard Parallel is N25 and the second Standard Parallel is $N 47^{\circ}$. Latitude of projection Origin is $0^{\circ}$. False Easting and False Northing are both $0 \mathrm{~m}$. The projection is an equal-area projection. The grid cells are "square" and in meters.

DEMs with resolution of $5 \mathrm{~m}, 25 \mathrm{~m}$ and $50 \mathrm{~m}$ were built using ANUDEM which were developed in Australia by Hutchinson [12]. ANUDEM interpolates the data from the topographic maps to finer resolutions in down scaling steps from coarser resolutions. The ANUDEM software interpolates the DEM where there is no source data using minimum curvature in order to make the surface as smooth as possible. The finest resolution used here is $5 \mathrm{~m}$ because $5 \mathrm{~m}$ is found to be the most suitable finest resolution according to the ANUDEM rules for topographic maps with scale of 1:10,000. The coarser DEMs seem to be similar with those obtained by up scaling the finer DEMs using low pass filtering to some extent, however it is not fully the same. Research is under way into the nature of the differences. The parameter values used in ANUDEM are showed in Table 1.

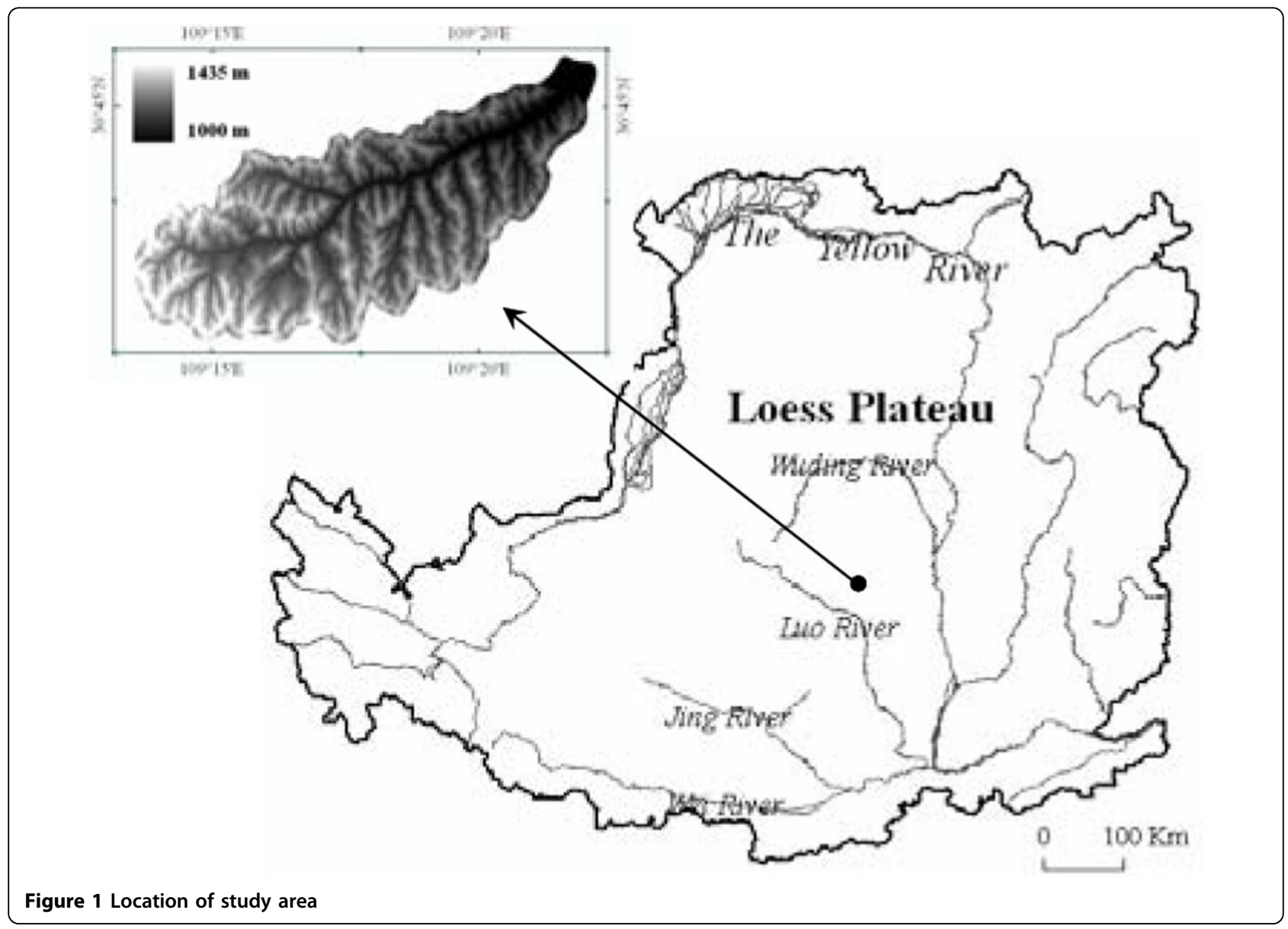


Table 1 Parameters of ANUDEM

\begin{tabular}{ccc}
\hline Maximum iterations & Profile curvature & Cell size (m) \\
\hline 40 & 0.7 & $5,25,50$ \\
\hline
\end{tabular}

\section{Information statistics for elevation and slope Slope calculation}

In this research slope is calculated using the following definition:

$$
\begin{aligned}
& \theta_{s}=\operatorname{Tan}^{-1}\left(p^{2}+q^{2}\right)^{1 / 2} \\
& {[p, q]=\nabla z=\left[\frac{\partial z}{\partial x}, \frac{\partial z}{\partial y}\right]}
\end{aligned}
$$

Where $\theta_{s}$ refers to slope; $\mathrm{p}$ and $\mathrm{q}$ refer to gradient field components. In a digital image, $\mathrm{p}$ and $\mathrm{q}$ are both calculated using the high pass filters as following.

$$
\begin{gathered}
{\left[\begin{array}{lll}
-1 & 0 & 1 \\
-1 & 0 & 1 \\
-1 & 0 & 1
\end{array}\right] / 6 h\left[\begin{array}{ccc}
1 & 1 & 1 \\
0 & 0 & 0 \\
-1 & -1 & -1
\end{array}\right] / 6 h} \\
\text { p filter }
\end{gathered}
$$

Where " $h$ " is the resolution step or grid cell size for the data.

\section{Histogram intersection}

Swain and Ballard [13] efficiently recognized objects by matching their color histograms using the histogram intersection (HI) method. In this research the author used Histogram Intersection (HI) to evaluate histogram similarity.

$\mathrm{HI}$ is calculated by:

$$
\mathrm{HI}(\mathrm{X}, \mathrm{Y})=\sum_{i} \min \left(x_{i}, y_{i}\right)
$$

Where $\mathrm{HI}(\mathrm{X}, \mathrm{Y})$ is Histogram Intersection of two histograms $\mathrm{X}$ and $\mathrm{Y} ; x_{i}$ and $y_{i}$ are frequency values of $\mathrm{X}$ and $\mathrm{Y}$ at slope value of $i$. The values for $\mathrm{HI}(\mathrm{X}, \mathrm{Y})$ range from $0 \%$ to $100 \%$. Histograms are more similar to each other if $\mathrm{HI}$ $(\mathrm{X}, \mathrm{Y})$ is larger. If two histograms are totally the same, $\mathrm{HI}$ $(\mathrm{X}, \mathrm{Y})$ equals to $100 \%$.

\section{Reduction rate of mean value and STD}

Mean value Reduction Rate and STD reduction rate for both elevation and slope are calculated here to refer to absolute value of mean value and STD change per reduction of resolution in meter. It will be used to help quantitatively analyze mean value and STD change with resolution. It is calculated by:

$$
M_{v}=\left|\frac{\mathrm{M}_{r^{\prime}}-\mathrm{M}_{r}}{r^{\prime}-r}\right|
$$

$$
\mathrm{S}_{v}=\left|\frac{\mathrm{S}_{r^{\prime}}-\mathrm{S}_{r}}{r^{\prime}-r}\right|
$$

Where $M_{v}$ is Mean value Reduction Rate; $M_{r^{\prime}}$ is mean value with coarser resolution of $r^{\prime} ; \mathrm{M}_{r}$ is mean value with finer resolution of $r$; $S_{v}$ is STD Reduction Rate; $\mathrm{S}_{r^{\prime}}$ is STD value with coarser resolution of $r^{\prime} ; \mathrm{S}_{r}$ is STD value with finer resolution of $r$.

\section{Geostatistical analysis}

\section{Covariance and semi-variogram}

In geostatistics, the mathematical expression for covariance and the semi-variance function is:

$$
\begin{aligned}
& C\left(h_{x}, h_{y}\right)=E\left(\left(Z\left(x+h_{x}, y+h_{y}\right)-m\right)(Z(x, y)-m)\right) \\
& \gamma\left(h_{x}, h_{y}\right)=\frac{1}{2} E\left(\left(Z\left(x+h_{x}, y+h_{y}\right)-Z(x, y)\right)^{2}\right.
\end{aligned}
$$

$C\left(h_{x} h_{y}\right)$ is the covariance function and $\gamma\left(h_{x}, h_{y}\right)$ is the semi-variance function; ( $x, y)$ stands for the spatial coordinators of the tested point of the slope; $\mathrm{Z}(\mathrm{x}, \mathrm{y})$ stands for the data of the tested point; $h_{x}$ and $h_{y}$ stands for the interval in $\mathrm{x}$ and $\mathrm{y}$ direction between two tested points (in 1D cases $\left.h=\left(h_{x}{ }^{2}+h_{y}{ }^{2}\right)^{1 / 2}\right)$, $\mathrm{m}$ is the mean value over the image. We will assume that the covariance is stationary and the mean $(\mathrm{m})$ is a constant over the image.

In this case the relationship between the two expressions is:

$$
\begin{aligned}
& \gamma\left(h_{x}, h_{y}\right)=C(0,0)-C\left(h_{x} h_{y}\right) \\
& C(0,0)=\sigma^{2}
\end{aligned}
$$

$\sigma^{2}$ is the variance of the image data which needs to be spatially stationary [14].

\section{Modeling covariance and semi-variogram}

In this article a form of model for the semi-variogram called the "Independent Structures" model [14] (sometimes it is called "Nested Model") is assumed. In this model the original field $Z(x, y)$ is considered to be composed of $\mathrm{N}$ "independent" fields, the covariance between the $\mathrm{N}$ fields is zero.

$$
Z(x, y)=\sum_{j=1}^{n} \sigma_{j} Y_{j}(x, y)
$$

So the total variance of $\mathrm{Z}$ is:

$$
\sigma_{Z}^{2}=\sum_{j=1}^{n} \sigma_{j}^{2}
$$

In the "Independent Structures" Model, the covariance function and semi-variogram fuction for $\mathrm{Z}$ is given by:

$$
C_{Z}\left(h_{x}, h_{y}\right)=\sum_{j=1}^{N} \sigma_{j}^{2} c_{j}\left(R_{j} ; h_{x}, h_{y}\right)
$$




$$
\gamma_{Z}\left(h_{x}, h_{y}\right)=\sum_{j=1}^{N} \sigma_{j}^{2} \gamma_{j}\left(R_{j} ; h_{x}, h_{y}\right)=\sum_{j=1}^{N} \sigma_{j}^{2}\left(1-c_{j}\left(R_{j} ; h_{x}, h_{y}\right)\right.
$$

$R_{j}$ refers to the ranges of the component semi-variograms and:

$$
0<R_{1}<R_{2}<R_{3} \ldots \ldots<R_{N}
$$

In this way, the first component is the one with greatest "roughness" or high spatial frequency content effect and the last is the one with greatest low frequency (regional) effect. This representation models the data with different "scale" components with $Y_{1} Y_{2} Y_{3} \ldots \ldots Y_{N}$ representing scale components with decreasing map scale.

In this paper the authors assume that the base semivariogram model is the radial 2D Gaussian, the covariance for each component is:

$$
c_{j}(h)=\sigma_{j}^{2} e^{-\left(h / R_{j}\right)^{2}}
$$

The radial distance is $h=\sqrt{h_{x}^{2}+h_{y}^{2}} ; \sigma_{j}^{2}$ is the variance of the component $j$; The quantity $R_{j}$ is taken as the range of component $j$ and the component has the form of a correlation function.

Effect of filtering on the covariance and semi-variogram Assuming that the function $\mathrm{Z}$ that is being filtered has mean zero and finite variance, the covariance function for $\mathrm{Z}$ is:

$$
C_{Z}(h)=\left(Z^{*} Z\right)(h)
$$

If $\mathrm{Z}$ is filtered by a filter $\phi$, then:

$$
\begin{aligned}
& \gamma_{F Z}(h)=C_{F Z}(0)-C_{F Z}(h) \\
& C_{F Z}(h)=\left(\left(\phi^{*} Z\right)^{*}\left(\phi^{*} Z\right)\right)(h) \\
& =\left[\left(\phi^{*} \phi^{*} C_{Z}\right](h)=\left(C_{\phi}^{*} C_{Z}\right)(h)\right.
\end{aligned}
$$

Where $C_{F Z}(h)$ the covariance of the filtered functions and $\gamma_{F Z}(h)$ is the semivariogram of the filtered function.

If the base semi-variogram model is radial 2D Gaussian, and the smoothing kernel is a normalized radially symmetric $2 \mathrm{D}$ Gaussian with range $S$, then:

$$
\begin{aligned}
& c_{j}(h)=\sigma_{j}^{2} e^{-\left(h / R_{j}\right)^{2}} \\
& \phi(h)=\frac{1}{\pi S^{2}} e^{-(h / S)^{2}} \\
& S=\frac{F W H M}{\sqrt{\pi}} \\
& F W H M=\frac{\int \phi}{\max (\phi)}
\end{aligned}
$$

FWHM (Full Width Half Maximum) is the width of the filter at half height. $\mathrm{H}$ is the height of the filter.

In this case the covariance of filtered function is:

$$
\begin{aligned}
& C_{F j}(h)=\left(C_{\phi} * C_{j}\right)(h) \\
& =\frac{\sigma_{j}^{2}}{\left(1+2 \frac{S^{2}}{R_{j}^{2}}\right)} e^{-h^{2} / R_{j}^{2}\left(1+2 \frac{S^{2}}{R_{j}^{2}}\right)} \\
& =\tilde{\sigma}_{j}^{2} e^{-\left(h / \tilde{R}_{j}\right)^{2}}
\end{aligned}
$$

The covariance of the filtered function is the same type as before however it has reduced variance and increased range.

\section{Model efficiency analysjs}

In order to evaluate the result of the Independent Structures model of the semi-variogram, the model efficiency coefficient (ME) which was proposed by Nash and Sutcliffe [15] was used in this research.

ME is calculated by:

$$
M E=1-\frac{\sum\left(Y_{o b s}-Y_{\text {pred }}\right)^{2}}{\sum\left(Y_{o b s}-Y_{\text {mean }}\right)^{2}}
$$

Where ME is the model efficiency, $Y_{o b s}$ is the observed value, $Y_{\text {pred }}$ is the predicted value, $Y_{\text {mean }}$ is the mean observed value. Values for ME range from $-\infty$ to 1 . The closer ME is to 1 , the better the model will predict individual values.

\section{Results and analysis}

Mean elevation and slope change with resolution

Table 2 shows the mean value and Standard deviation (STD) of both elevation and slope. Elevation in Xian'nan Watershed does not change greatly with resolution reduction but slope seems to be largely influenced by resolution. Mean elevation and STD of elevation tend to decrease slightly with resolution reduction with a reduction rate of $0.03 \mathrm{~m} / \mathrm{m}$. Mean slope and STD of slope tend to decrease with resolution reduction more intensively than elevation and the reduction rates are different with different resolution changes. The mean slope reduction rate with resolution from $5 \mathrm{~m}$ to $25 \mathrm{~m}$ of $0.3^{\circ} / \mathrm{m}$ is the largest (Table 3 ). This means that when resolution becomes 1 meter coarser, the mean slope will decrease by $0.3^{\circ}$ which is large.

Table 2 Mean and Std of elevation and slope

\begin{tabular}{ccccc}
\hline & \multicolumn{2}{c}{ Mean value } & \multicolumn{2}{c}{ STD } \\
\hline Resolution $(\mathbf{m})$ & Elevation $(\mathbf{m})$ & Slope $\left(^{\circ}\right)$ & Elevation $(\boldsymbol{m})$ & Slope $\left(^{\circ}\right)$ \\
\hline 5 & 1220.1 & 28.5 & 74.0 & 11.1 \\
\hline 25 & 1219.5 & 22.7 & 73.4 & 8.8 \\
\hline 50 & 1218.9 & 18.5 & 72.9 & 7.4 \\
\hline
\end{tabular}


Table 3 Mean value and STD reduction rate

\begin{tabular}{ccccc}
\hline & \multicolumn{2}{c}{ Mean value } & \multicolumn{2}{c}{ STD } \\
\hline & Elevation $(\mathbf{m})$ & Slope $\left(^{\circ}\right)$ & Elevation $(\boldsymbol{m})$ & Slope $\left(^{\circ}\right)$ \\
\hline $5 \mathrm{~m}-25 \mathrm{~m}$ & -0.03 & -0.29 & -0.03 & -0.12 \\
\hline $25 \mathrm{~m}-50 \mathrm{~m}$ & -0.03 & -0.17 & -0.03 & -0.07 \\
\hline
\end{tabular}

\section{Histograms of elevation and slope changes with resolution}

Histograms of elevation with varied resolutions of $5 \mathrm{~m}$, $25 \mathrm{~m}$ and $50 \mathrm{~m}$ are shown in Figure 2a. Histograms for elevation mix together because they are quite similar to each other. Elevation histogram distribution changes little because of the resolution reduction. HI in Table 4 clearly shows that the HI values between elevation histograms with $25 \mathrm{~m}, 50 \mathrm{~m}$ resolution and elevation histogram with $5 \mathrm{~m}$ resolution are both larger than $90 \%$.

There seems to be a great difference between slope histograms with $25 \mathrm{~m}, 50 \mathrm{~m}$ resolution and the slope histogram with $5 \mathrm{~m}$ resolution (Figure $2 \mathrm{~b}$ ). As resolution reduces, the histograms of slope move to the left side which is lower. HI values between the slope histograms with $25 \mathrm{~m}$ and $50 \mathrm{~m}$ resolution and the slope histogram

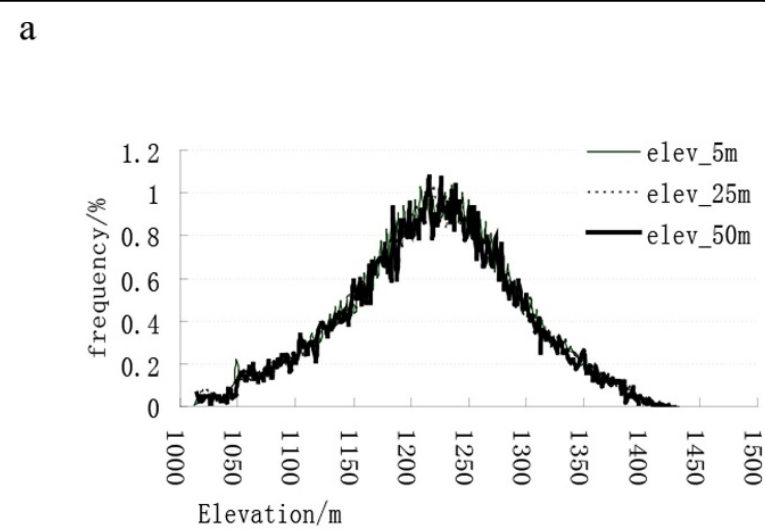

$\mathrm{b}$

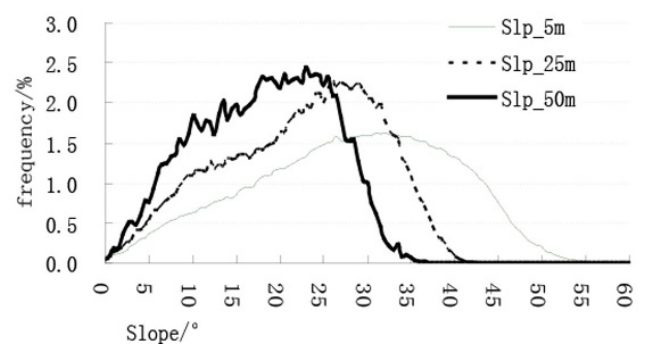

Figure 2 a Histograms of elevation with varied resolution. b Histograms of slope with varied resolution
Table 4 HI comparing with 5 m data (\%)

\begin{tabular}{llll}
\hline & $5 \mathrm{~m}$ & $25 \mathrm{~m}$ & $50 \mathrm{~m}$ \\
\hline DEM & 100 & 96.258 & 94.0111 \\
\hline Slope & 100 & 73.774 & 55.7426 \\
\hline
\end{tabular}

with $5 \mathrm{~m}$ resolution are $73.8 \%$ and $55.7 \%$ which shows the great influence of resolution on the histogram of slope.

\section{Changes in semi-variogram of elevation and slope with resolution \\ Independent structures of semi-variogram}

Semi-variogram of elevation with resolution of $5 \mathrm{~m}$, $25 \mathrm{~m}$ and $50 \mathrm{~m}$ are calculated and modeled using the Gaussian model. These are plotted in Figure 3a. The elevation semi-variogram in the Xian'nan watershed has been modeled with 4 components which are labeled as Y1, Y2, Y3, and Y4. Sill and range for each component are shown in Table 5 . The ranges are ordered by $\mathrm{Y} 1<\mathrm{Y} 2<\mathrm{Y} 3<\mathrm{Y} 4$ as in the independent model. Y4 indicates information that of longer wave-length. Y4 seems to be a trend component and has not reached a sill inside the maximum lag of semi-variance. This component is "unstable" and cannot be treated in the same way as the other components. The sills are ordered as: $\mathrm{Y} 1<\mathrm{Y} 3<\mathrm{Y} 2$. $\mathrm{Y} 1$ indicates information relating to short wave-length. In the elevation data in the study area, the short wavelength information accounts for much less variance than the long wave-length information.

Semi-variograms of slope with resolution of $5 \mathrm{~m}, 25 \mathrm{~m}$ and $50 \mathrm{~m}$ were calculated and modeled. These are plotted in Figure 3b. The slope semi-variogram in Xian'nan watershed has been modeled using 3 components which are labeled as Y1, Y2, and Y3. Sill and range of each component are shown in Table 6. The range is ordered by $\mathrm{Y} 1<\mathrm{Y} 2<\mathrm{Y} 3$ in the independent model. All of the three components have reached a sill inside the maximum lag of semi-variance. The sill values are ordered as: $\mathrm{Y} 3<\mathrm{Y} 2<\mathrm{Y} 1$ with 5 meter resolution. In slope data in the study area, the short wave-length information accounts for more variance than the long wavelength information.

\section{The effect of resolution on the independent structures of} semi-variogram

The effect of resolution reduction is quite similar to low pass filter. If we treat the resolution reduction as a Gaussian low pass filter, the semi-variograms with coarser resolution can be predicted from the fine resolution using the method discussed in this paper. The sill and range in each component can be predicted. In this paper, the authors predicted the coarser resolution variograms of each component from the $5 \mathrm{~m}$ resolution variograms. The ME of the model is shown in Table 7. The ME values are all above 0.65 . 


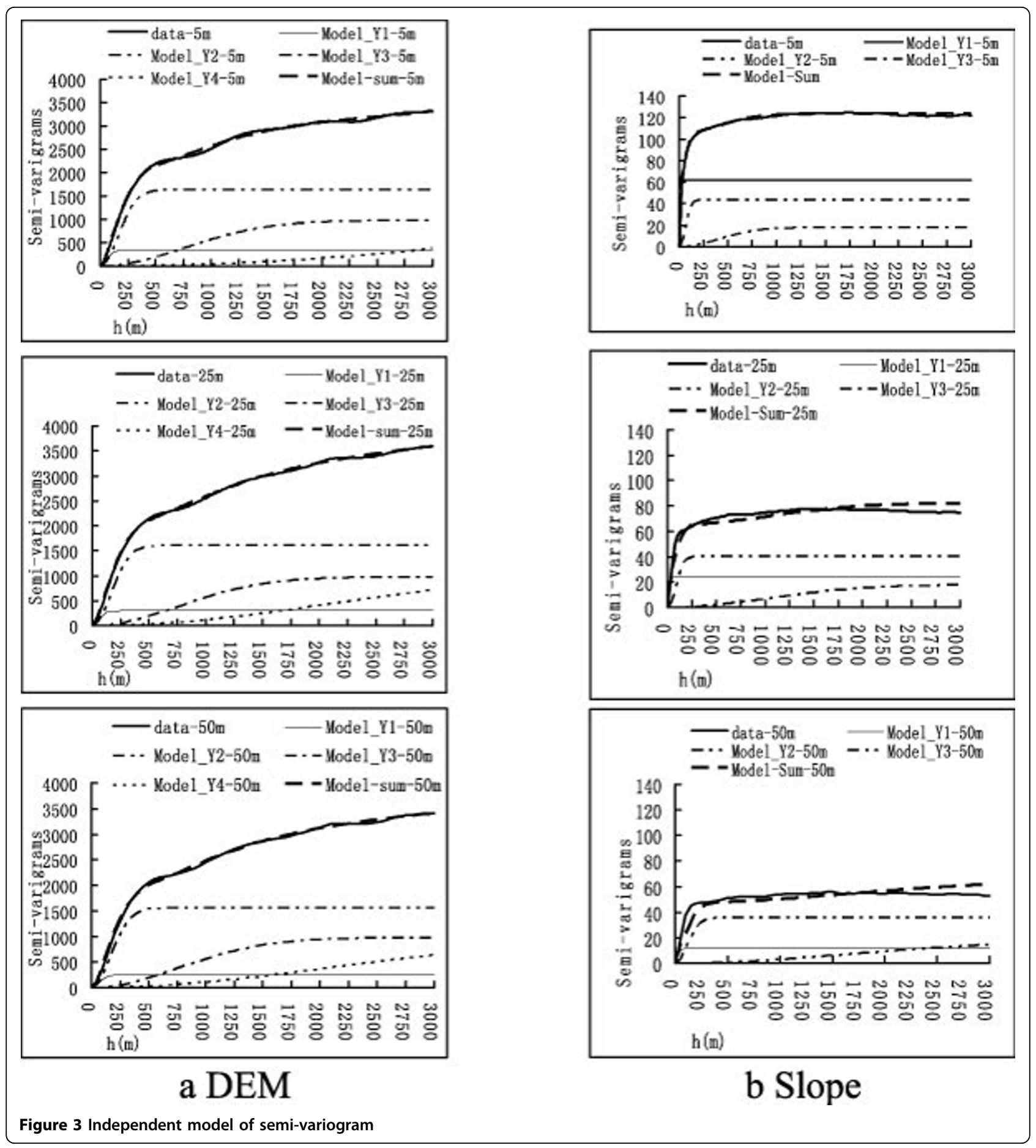

The influence of resolution reduction is smallest on long wave-length components and is largest for Y1 in both elevation and slope cases. Table 5 and Figure $3 a$ show that in the elevation case, the sill value of $Y 1$ reduced to $72.6 \%$ of the $5 \mathrm{~m}$ case when resolution is $50 \mathrm{~m}$. Y2 and Y3 seem to have be stable and the reduction of sill when the resolution is $50 \mathrm{~m}$ is less than $5 \%$ of the $5 \mathrm{~m}$ case. Table VI and
Figure $3 \mathrm{~b}$ show that in slope case, the sill value of $\mathrm{Y} 1$ reduced to $18.1 \%$ of the $5 \mathrm{~m}$ case when resolution is $50 \mathrm{~m}$. The sill value of $\mathrm{Y} 2$ reduced to $82.2 \%$ of the $5 \mathrm{~m}$ case when the resolution is $50 \mathrm{~m}$ and the sill value of $\mathrm{Y} 3$ reduced to $99.5 \%$ of the $5 \mathrm{~m}$ case when the resolution is $50 \mathrm{~m}$.

Comparing the elevation and slope cases, the influence of resolution reduction on slope is much larger than on 
Table 5 Sill and range of elevation semi-variogram

\begin{tabular}{|c|c|c|c|}
\hline & Resolution (m) & Range & Sill \\
\hline & 5 & 140.24 & 328.23 \\
\hline \multirow[t]{3}{*}{ Y1 } & 25 & 148.64 & 292.19 \\
\hline & 50 & 164.54 & 238.44 \\
\hline & 5 & 404.38 & 1629.60 \\
\hline \multirow[t]{3}{*}{ Y2 } & 25 & 407.37 & 1605.78 \\
\hline & 50 & 413.44 & 1558.99 \\
\hline & 5 & 1866.01 & 977.49 \\
\hline \multirow[t]{3}{*}{ Y3 } & 25 & 1866.66 & 976.81 \\
\hline & 50 & 1867.99 & 975.42 \\
\hline & 5 & 50315.37 & 35390.90 \\
\hline \multirow[t]{3}{*}{ Y4 } & 25 & 5212.52 & 1133.83 \\
\hline & 50 & 5058.91 & 977.95 \\
\hline & 5 & 2410.63 & 2935.33 \\
\hline \multirow[t]{2}{*}{ Model-Sum } & 25 & 2422.67 & 2874.78 \\
\hline & 50 & 2445.98 & 2772.84 \\
\hline
\end{tabular}

*Model-sum is the sum of range and sill of each component except $\mathrm{Y} 4$ because $\mathrm{Y} 4$ has not Come to a range inside maximum lag of semi-variance.

elevation especially in the Y1 components. The Sill (Model sum) of elevation reduced only to $94.4 \%$ of the $5 \mathrm{~m}$ case but the sill (Model sum) of slope reduced to $52.6 \%$ of the $5 \mathrm{~m}$ case. The reason is that the process of slope calculation acts as a high pass filter. More short wave-length information is left in the image after the slope is calculated. Therefore there is much more short wave-length information in slope data than in elevation data. The low pass filter and the resolution reduction effect greatly influence the short wave-length information.

\section{Discussion}

ME of slope is lower than ME of elevation. It may because that the Gaussian Model is not the most appropriate one for slope. In this paper the main purpose is to

Table 6 Sill and range of slope semi-variogram

\begin{tabular}{|c|c|c|c|}
\hline & Resolution (m) & Range & Sill \\
\hline & 5 & 32.88 & 61.71 \\
\hline \multirow[t]{3}{*}{ Y1 } & 25 & 39.58 & 23.90 \\
\hline & 50 & 49.68 & 11.18 \\
\hline & 5 & 150.19 & 43.51 \\
\hline \multirow[t]{3}{*}{ Y2 } & 25 & 207.23 & 40.44 \\
\hline & 50 & 284.18 & 35.76 \\
\hline & 5 & 997.53 & 17.97 \\
\hline \multirow[t]{3}{*}{ Y3 } & 25 & 2503.71 & 17.94 \\
\hline & 50 & 4006.32 & 17.88 \\
\hline & 5 & 1180.60 & 123.18 \\
\hline \multirow[t]{2}{*}{ Model-Sum } & 25 & 2750.52 & 82.27 \\
\hline & 50 & 4340.18 & 64.83 \\
\hline
\end{tabular}

Table 7 ME of independent structure model

\begin{tabular}{lll}
\hline Resolution & Elevation & Slope \\
\hline 5 & 0.9997 & 0.9920 \\
25 & 0.9994 & 0.8231 \\
50 & 0.9987 & 0.6743 \\
\hline
\end{tabular}

show the scale effect which has been done. Work on appropriate model for slope is investigated by the authors.

In this paper the authors modeled the effects of resolution reduction on the semi-variogram using a Gaussian filter. Although the way ANUDEM changes with scale do not behave exactly the same way as a Gaussian filter, the model can work quite well. In the future, more effort is being put into the study of the differences between the two.

The semi-variograms in this paper has been modeled using Independent structure model. The model allows us to clarify the way resolution influence DEM data. In further study this would be applied to different terrain types.

In further study, the semi-variogram of each component will be mapped out using kriging to show the nature of different information in each component.

\section{Conclusions}

In this paper the independent structure model was used to model the semi-variograms of elevation and slope data with resolution of $5 \mathrm{~m}, 25 \mathrm{~m}$ and $50 \mathrm{~m}$. The results showed how the short wave-length information disappeared or weakened as resolution reduced. These results can explain which component of the information has changed with resolution reduction. By calculating the mean value, STD and histogram of both elevation and slope at different resolutions, it is clear that the influence of resolution on elevation is less than on slope. The reason is that the short wave-length information accounts for more variance in slope data than in elevation data. Resolution reduction or low pass filtering influence the short wave-length information the most.

\section{Competing interests}

The authors declare that they have no competing interests.

\section{Acknowledgements}

This research is supported by Research on Spatial Frequency of Erosional Terrain in Loess Hilly Region(NSFC Project, 41301284) and Study on theoretical distribution model of Slope (NSFC Project, 41371274). Part of the research was finished during Chunmei Wang's visit to CSIRO.

\section{Declarations}

The publication costs for this article were funded by Scientific \& Technical Development Inc.

This article has been published as part of SpringerPlus Volume 2 Supplement 1, 2013: Proceedings of the 2010 International Conference on Combating Land Degradation in Agricultural Areas (ICCLD'10). The full contents of the 


\section{Authors' details}

'College of Urban and Environmental Science, Northwest University, Xi'an, Shaanxi 710027 China. ${ }^{2}$ College of Resources and Environment, Northwestern A\&F University, Yangling, Shaanxi, 712100, China. Institute of Soil and Water Conservation, Chinese Academy of Sciences And Ministry of Water Resources, Yangling, Shaanxi 712100, China. ${ }^{4}$ CSIRO Division of Marine and Atmospheric Research, GPO Box 3023, Canberra ACT 2601, Australia.

Published: 11 December 2013

\section{References}

1. Huang BW: Main types and factors of soil erosion. Journal of Geographical Sciences 1953, 43(2):200-203.

2. Zhu XM: The main types of soil erosion and terrain characteristic to erosion in the Loess Plateau of China. Bulletin of Soil and Water Conservation 1981, 4:13-18.

3. Tang KL, Zhang KL, Lei AL: Research on slope upper limit for returning farmland in the loess hilly region. Science Bulletin 1998, 43(2):200-203.

4. Moore ID, Burch GJ: Modeling erosion and deposition: topographic effects. Transactions of the ASAE 1986, 29(6):1624-1630.

5. Liu BY, Near MA, Risse LM: Slope gradient effects on soil loss for steep slopes. Transactions of the ASAE 1994, 37(6):1835-1840.

6. Chang K, Tsai B: The effect of DEM resolution on slope and aspect mapping. Cartography and Geographic Information Science 1991, 8(1):69-77.

7. Gao J: Resolution and Accuracy of Terrain Representation by Grid DEMs at a Micro-scale. International Journal of Geographical Information Science 1997, 11(2):199-217.

8. Zhang $X$, Drake NA, Wainwright J, et al: Comparison of slope estimates from low resolution DEMs: scaling issues and a fractal method for their solution. Earth Surface Processes and Landforms 1999, 24(9):763-779.

9. Wolock DM, McCabe GJ: Differences in topographic characteristics computed from 100- and 1000-m resolution digital elevation model data. Hydrological processes 2000, 14(6):987-1002.

10. Wu S, Li J, Huang GH: A study on DEM-derived primary topographic attributes for hydrologic applications: sensitivity to elevation data resolution. Applied Geography 2008, 28(3):210-223.

11. Mulla DJ: Using geostatistics and spectral analysis to study spatial patterns in the topography of southeastern Washington state USA. Earth Surface Processes and Landforms 1988, , 13: 389-405.

12. Hutchinson MF: A new procedure for gridding elevation and stream line data with automatic removal of spurious pits. Journal of Hydrology 1989, 106(3-4):211-232.

13. Swain MJ, Ballard DH: Indexing via color histo-grams. Proceedings of the Third International Conference on Computer Vision Osaka, Japan; 1990, 390-393.

14. Webster R, Oliver MA: Geostatistics for Environmental Scientists. Viley, Chichester; 2001.

15. Nash JE, Sutcliffe JV: River flow forecasting through conceptual models: Partl. A discussion of principles. Journal of Hydrology 1970, 10:282-290.

doi:10.1186/2193-1801-2-S1-S13

Cite this article as: Chunmei et al:: Influence of resolution on elevation and slope at watershed scale in Loess Plateau. SpringerPlus 20132 (Suppl 1):S13.

\section{Submit your manuscript to a SpringerOpen ${ }^{\mathcal{O}}$ journal and benefit from:}

- Convenient online submission

- Rigorous peer review

- Immediate publication on acceptance

- Open access: articles freely available online

- High visibility within the field

- Retaining the copyright to your article 